\title{
Evaluating Production of Cyclopentyl Tetraethers by Marine Group II Euryarchaeota in the Pearl River Estuary and Coastal South China Sea: Potential Impact on the TEX 86 Paleothermometer
}

OPEN ACCESS

Edited by:

Stefan M. Sievert,

Woods Hole Oceanographic

Institution, United States

Reviewed by:

Florence Schubotz,

University of Bremen, Germany

Anitra E. Ingalls,

University of Washington,

United States

*Correspondence:

Chuanlun L. Zhang

zhangcl@sustc.edu.cn

${ }^{\dagger}$ These authors have contributed equally to this work.

Specialty section:

This article was submitted to

Aquatic Microbiology,

a section of the journal

Frontiers in Microbiology

Received: 31 May 2017 Accepted: 10 October 2017 Published: 31 October 2017

Citation:

Wang J-X, Xie W, Zhang YG, Meador TB and Zhang CL (2017) Evaluating Production of Cyclopentyl

Tetraethers by Marine Group II

Euryarchaeota in the Pearl River Estuary and Coastal South China Sea:

Potential Impact on the TEX 86 Paleothermometer.

Front. Microbiol. 8:2077. doi: 10.3389/fmicb.2017.02077

\begin{abstract}
Jin-Xiang Wang ${ }^{1,2+}$, Wei Xie ${ }^{3 \dagger}$, Yi Ge Zhang ${ }^{4}$, Travis B. Meador ${ }^{1}$ and Chuanlun L. Zhang ${ }^{3,5 *}$
${ }^{1}$ MARUM-Center for Marine Environmental Sciences, University of Bremen, Bremen, Germany, ${ }^{2}$ Department of Marine Sciences, University of Georgia, Athens, GA, United States, ${ }^{3}$ State Key Laboratory of Marine Geology, Tongji University, Shanghai, China, ${ }^{4}$ Department of Oceanography, Texas A\&M University, College Station, TX, United States, ${ }^{5}$ Department of Ocean Science \& Engineering, Southern University of Science and Technology, Shenzhen, China
\end{abstract}

TEX 86 [TetraEther indeX of glycerol dialkyl glycerol tetraethers (GDGTs) with 86 carbon atoms] has been widely applied to reconstruct (paleo-) sea surface temperature. Marine Group I (MG-I) Thaumarchaeota were thought to be the primary source of GDGTs constituting the $\mathrm{TEX}_{86}$ formula; however, recent research has suggested that Marine Group II (MG-II) Euryarchaeota may also contribute significantly to the GDGT pool in the ocean. Little is known regarding the potential impact of MG-II Euryarchaeota-derived GDGTs on TEX 86 values recorded in marine sediments. In this study, we assessed the relationship between distributions of GDGTs and MG-II Euryarchaeota and evaluated its potential effect on the TEX 86 proxy. Lipid and DNA analyses were performed on suspended particulate matter and surface sediments collected along a salinity gradient from the lower Pearl River (river water) and its estuary (mixing water) to the coastal South China Sea (SCS, seawater). TEX ${ }_{86}$-derived temperatures from the water column and surface sediments were significantly correlated and both were lower than satellite-based temperatures. The ring index (RI) values in these environments were higher than predicted from the calculated TEX ${ }_{86}-R \mid$ correlation, indicating that the GDGT pool in the water column of the PR estuary and coastal SCS comprises relatively more cyclopentane rings, which thereby altered TEX 86 values. Furthermore, the abundance of MG-II Euryarchaeota $16 S$ rRNA gene in the mixing water was two to three orders of magnitude higher than those observed in the river or seawater. Significant linear correlations were observed between the gene abundance ratio of MG-II Euryarchaeota to total archaea and the fractional abundance of GDGTs with cyclopentane rings. Collectively, these results suggest that MG-II Euryarchaeota likely produce a large proportion of GDGTs with 1-4 cyclopentane moieties, which may bias TEX 86 values in the water column and sediments. As such, valid interpretation of TEX 86 values in the sediment record, particularly in coastal oceans, should consider the contribution from MG-II Euryarchaeota.

Keywords: Marine Group II, Euryarchaeota, GDGTs, TEX 86 , ring index, South China Sea 


\section{INTRODUCTION}

$\mathrm{TEX}_{86}$ is a popular temperature proxy applied in paleoclimatological studies, which is based on the relative distribution of cyclopental rings among isoprenoid glycerol dialkyl glycerol tetraether (GDGT; Figure S1) lipids produced by archaea in marine and terrestrial environments (see review by Schouten et al., 2013). Global core-top calibrations of $\mathrm{TEX}_{86}$ values were empirically correlated with the annual mean sea surface temperature (SST; Schouten et al., 2002; Kim et al., 2008, 2010). However, mounting evidence indicates anomalies of $\mathrm{TEX}_{86}$-derived SST in coastal seas and the open ocean, which have been attributed to multiple inputs of GDGTs from terrestrial (e.g., Weijers et al., 2006) or bathypelagic sources (e.g., Lee et al., 2008), as well as production in marine sediments (e.g., Liu X. L. et al., 2011).

A great deal of effort has been made to assess TEX $_{86}$ accuracy in marine and lake sediments. For example, application of the $\mathrm{TEX}_{86}$ proxy is cautioned under the following circumstances: a branched and isoprenoid tetraether (BIT) index $>0.2$ (Zhu et al., 2011), a ratio of GDGT-2/crenarchaeol $>0.4$ (Weijers et al., 2011a), a Methane Index > 0.5 (Zhang et al., 2011), a ratio of GDGT-0/crenarchaeol > 2 (Blaga et al., 2009), or when \%GDGT$2>45$ (Sinninghe Damsté et al., 2012). Recently, based on an assessment of the relationship between the weighted average number of cyclopentane rings in GDGTs (ring index, RI) and published $\mathrm{TEX}_{86}$ data from core-top sediments, Zhang et al. (2016) established a significant correlation between $\mathrm{TEX}_{86}$ and RI $\left[\mathrm{RI}=3.32 \times\left(\mathrm{TEX}_{86}\right)^{2}-0.77 \times \mathrm{TEX}_{86}+1.59 ; \pm 2 \sigma \sim\right.$ $0.3]$. This relationship was expected and reflects the physiological response of marine archaea to synthesize GDGTs with more rings (higher RI values) at higher temperatures (higher $\mathrm{TEX}_{86}$ values). Deviations from this relationship suggest that temperature is not a dominant factor governing GDGT ring distribution, or, alternatively, the relationship between GDGT ring distribution and temperature is different from the modern analog as defined by the global core-top dataset.

The TEX $_{86}$-related GDGTs (GDGTs-1, $-2,-3$ and the crenarchaeol regioisomer) in the water column are thought to primarily derive from the Marine Group I (MG-I) Thaumarchaeota (e.g., Schouten et al., 2008; Pitcher et al., $2011 a, b)$, as it is one of the dominant groups of planktonic archaea in the ocean (Karner et al., 2001). In particular, crenarchaeol, containing one cyclohexane and four cyclopentane moieties, is accepted as a specific biomarker for MG-I Thaumarchaeota (Sinninghe Damsté et al., 2002; Schouten et al., 2008). Marine Group II (MG-II) Euryarchaeota are another group of planktonic archaea that predominantly inhabit coastal water and (near) surface waters of the open ocean (e.g., DeLong, 1992; Galand et al., 2010; Hugoni et al., 2013). Recently, this cosmopolitan group was also invoked as another major source of GDGTs (including crenarchaeol) in the ocean (Lincoln et al., 2014a), which supports an earlier hypothesis about GDGT-producing MG-II Euryarchaeota (Turich et al., 2007). However, concrete evidence of crenarchaeol production by MG-II is lacking due to the inability to obtain a pure culture or isolate, and the exact composition of GDGTs produced by these organisms remains uncertain (Lincoln et al., 2014b; Schouten et al., 2014).

To further evaluate the relationship between MG-II Euryarchaeota and the distribution of GDGTs, we quantified the abundance of MG-II 16S rRNA gene, determined the distribution of GDGT core and intact polar lipids (CL and IPL, respectively), and assessed $\mathrm{TEX}_{86}$ and Ring Index (RI) values from suspended particulate matter and surface sediments collected from the lower Pearl River (PR) and its estuary to the coastal South China Sea (SCS). Our results provide a mechanistic explanation for deviations of the $\mathrm{TEX}_{86}$ paleothermometer and have important implications for the sources of GDGTs in marine environments and probing past changes in global climate.

\section{MATERIALS AND METHODS}

\section{Sample Collection}

Sampling locations and other information for suspended particulate matter (SPM) and surface sediments are shown in Figure 1 and Table 1. SPM samples $(n=18)$ and surface sediments $(n=8)$ were collected along a salinity gradient from the lower Pearl River and its estuary to the coastal South China Sea in the summer of 2011. SPM samples were collected from the surface (stations R1-R6) and the bottom (stations R1 and R2) water in the lower Pearl River, from three water depths (surface, middle, and bottom) and during three tidal periods (high tide, slack tide, and low tide) at station $M$ located in the PR estuary, and at four water depths (surface, subsurface, middle, and bottom) at station $S$ in the seawater of the coastal SCS (Figure 1). The depth of the sampling layers in the water column is given in Table 1. About 4-103 liters of water were filtered onto combusted $\left(450^{\circ} \mathrm{C}\right.$, overnight) glass-fiber filters (Whatman GF/F, $0.7 \mu \mathrm{m}, 142 \mathrm{~mm}$ diameter) using an in situ submersible pump. The $\mathrm{pH}$, temperature, salinity, and depth were determined in situ by a Horiba instrument (W-20XD, Kyoto, Japan; Table 1). Surface sediments (top ca. $10 \mathrm{~cm}$ ) were collected at all stations (Figure 1; Table 1) using a grab sampler. All samples were frozen immediately in liquid nitrogen and kept at $-80^{\circ} \mathrm{C}$ in the laboratory before analysis.

\section{GDGT Extraction and Separation}

The SPM samples $(n=18)$ and surface sediments $(n=8)$ were freeze-dried and extracted using a modified Bligh and Dyer method (Bligh and Dyer, 1959); the separation of core lipids and intact polar lipids followed the procedure described in Weijers et al. (2011b). Briefly, the total lipid extract (TLE) was obtained by ultrasonic extraction (10 min each, 6 times) of SPM (1 filter) or sediments $(5 \mathrm{~g})$ with a single-phase solvent mixture of methanol, dichloromethane (DCM), and phosphate buffer (2:1:0.8, v/v/v; pH 7.4). The TLE was separated over an activated silica gel column eluted with n-hexane/ethyl acetate $(1: 1, v / v)$ and methanol for CL and IPL, respectively. For GDGT quantification, a known amount of an internal C46 GDGT standard was added into the CL fraction or IPL fraction (Huguet et al., 2006). The CL fraction was directly measured. The IPL fraction was determined by measuring the CL after cleavage of the polar head groups via acid or base hydrolysis (Pitcher 


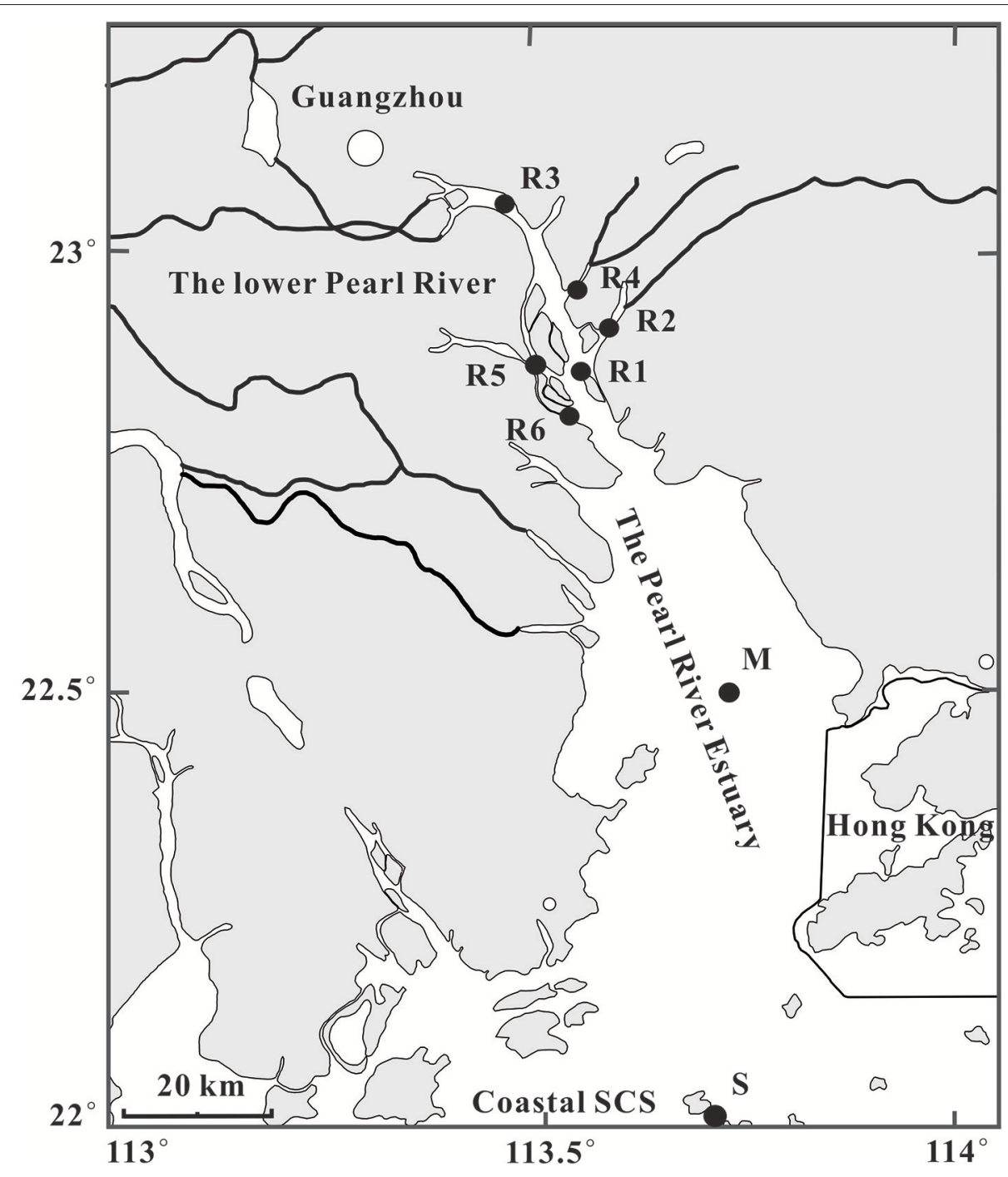

FIGURE 1 | Map showing locations of sites (dark circles) in the lower Pearl River (PR), the PR estuary, and coastal South China Sea (SCS). R, River water, which is followed by the station \#1-6; M, mixing water; S, seawater. Station S includes four water layers (surface, subsurface, middle, and bottom). Station M includes three water layers (surface, middle, and bottom). The surface water at station M was also collected during the high tide-, slack tide-, and low tide-periods. Stations R1 and R2 include two water layers (surface and bottom). Surface sediments were collected at each sampling site.

et al., 2009; Weijers et al., 2011b). Briefly, 1/3 IPL fraction (nonhydrolyzed IPL fraction) was directly condensed; another $1 / 3$ IPL fraction was hydrolyzed $(2 \mathrm{~h})$ in $1.5 \mathrm{~N} \mathrm{HCl}$ in methanol, which was called the acid-hydrolyzed IPL fraction (total IPL). DCM and MilliQ water were added, and the DCM fraction was collected (repeated 4 times). The DCM fraction was rinsed (6 times) with MilliQ water in order to remove acid and dried under $\mathrm{N}_{2}$ gas. The last 1/3 IPL fraction was subjected to base hydrolysis $(2 \mathrm{~h})$ in a $1 \mathrm{~N} \mathrm{KOH}$ in methanol/ $\mathrm{H}_{2} \mathrm{O}$ mixture (95:5, $\mathrm{v} / \mathrm{v}$ ), which was called the base-hydrolyzed IPL fraction (phospho IPL). Together with the condensed CL fraction, the CL fraction, two fractions of IPL-derived core lipids and non-cleaved IPL fraction were dissolved in n-hexane/isopropanol (99:1, v/v), and filtered using PTFE filters (pore diameter of $0.45 \mu \mathrm{m}$ ). The acidhydrolyzed IPL reflected total IPL, which, prior to hydrolysis, were attached to both phosphatidyl and glycosidic head groups; The base-hydrolyzed IPL represented IPLs with phosphatidyl head groups only (phospho IPL; Weijers et al., 2011b). Analysis of the non-hydrolyzed IPL fraction was performed to determine any carryover of CL into the IPL fraction.

\section{GDGT Analysis}

GDGTs from all treatments were analyzed using high performance liquid chromatography-atmospheric pressure chemical ionization-tandem mass spectrometry (HPLC-APCIMS/MS), which was performed as described by Zhang et al. (2012), using an Agilent 1200 LC equipped with an automatic injector and coupled to a QQQ $6460 \mathrm{MS}$; peaks were evaluated using Mass Hunter LC-MS manager software. Separation was achieved using a Prevail Cyano column $(2.1 \times 150 \mathrm{~mm}, 3 \mu \mathrm{m}$; 


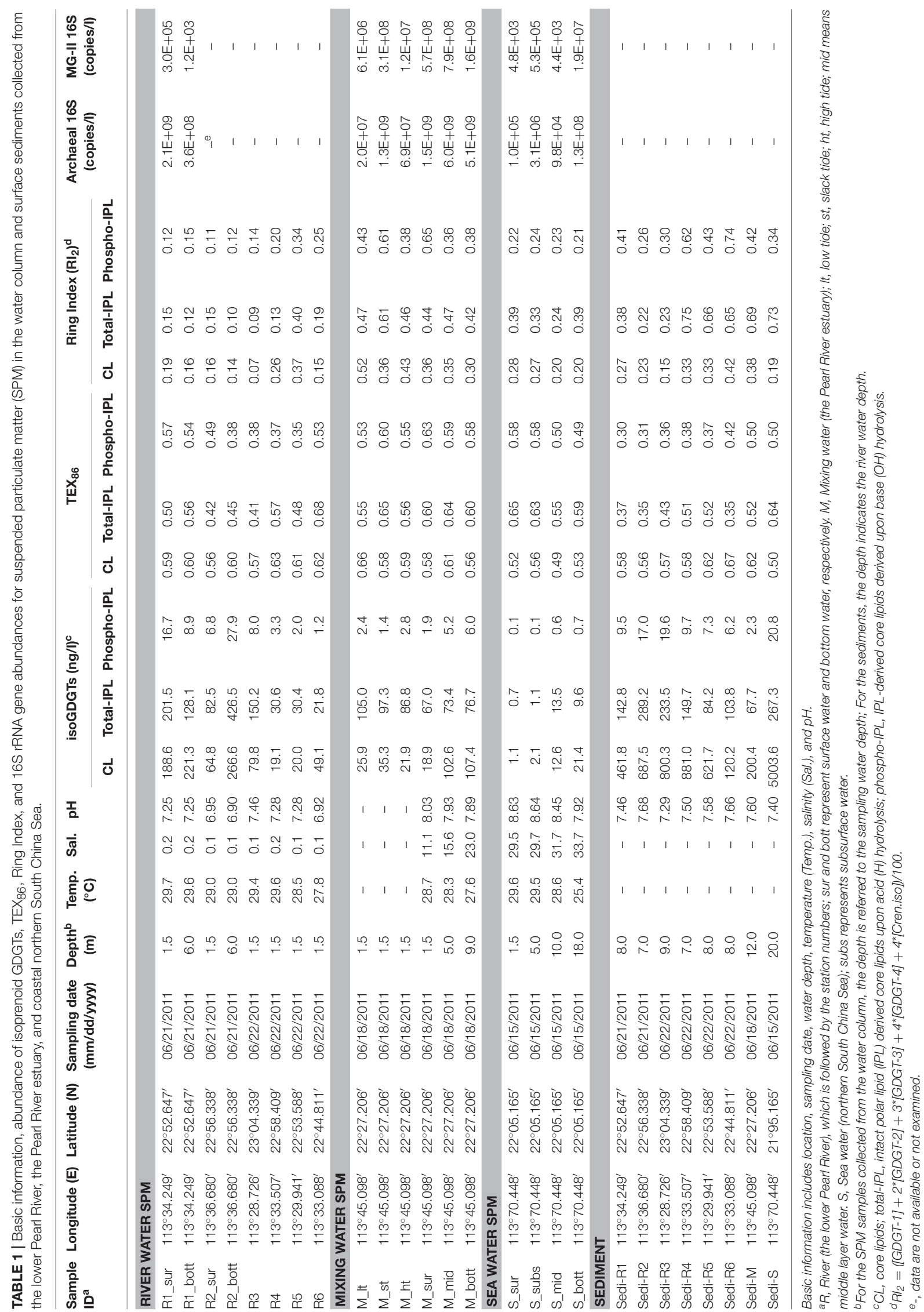


Alltech Deerifled, IL, USA) with n-hexane (solvent A) and a mixture of $n$-hexane/isopropanol $90 / 10$ (v/v; solvent B). The $(\mathrm{M}+\mathrm{H})^{+}$ions of each core isoprenoid GDGT $(\mathrm{m} / \mathrm{z} 1,302,1,300$, $1,298,1,296,1,294,1,292)$ were monitored via selected ion monitoring (SIM) mode (Schouten et al., 2007).

\section{GDGT-Based Indices}

Indices based on the fractional abundance of GDGTs were calculated as follows:

$$
\begin{aligned}
\operatorname{TEX}_{86}= & ([G D G T-2]+[\text { GDGT }-3]+[\text { Cren.iso }]) \\
& /([\text { GDGT }-1]+[\text { GDGT }-2]+[\text { GDGT }-3] \\
& +[\text { Cren.iso }])(\text { Schouten et al., } 2002) \\
\text { Ring Index }{ }_{1}\left(\mathrm{RI}_{1}\right)= & ([\text { GDGT }-1]+2 \times[\text { GDGT }-2]+3 \\
& \times[\text { GDGT }-3]+4 \times[\text { Cren. }]+4 \\
& \times[\text { Cren.iso }]) / 100(\text { Zhang et al., } 2016) \\
\text { Ring Index }\left(\mathrm{RI}_{2}\right)= & ([\text { GDGT }-1]+2 \times[\text { GDGT }-2]+3 \\
& \times[\text { GDGT }-3]+4 \times[\text { GDGT }-4]+4 \\
& \times[\text { Cren.iso }]) / 100
\end{aligned}
$$

with the GDGT numbers corresponding to the GDGT structures in Figure S1. Note that $\mathrm{RI}_{2}$ was originally developed for the current study and modified from $\mathrm{RI}_{1}$ (Zhang et al., 2016), in which the fractional abundance of crenarchaeol was replaced by GDGT-4 in order to eliminate the influence of crenarchaeol on weighted average number of cyclopentane rings in GDGTs.

\section{DNA Extraction and the Quantitative Polymerase Chain Reaction (qPCR)}

The SPM samples $(n=12)$ from station R1 (river water), station $\mathrm{M}$ (mixing water), and station $\mathrm{S}$ (seawater) were selected for the DNA analysis. The frozen filters were washed 3 times by phosphate buffered saline $(\mathrm{pH}$ 7.4). The supernatants were centrifuged under $11,000 \mathrm{~g}$ for $10 \mathrm{~min}$. The DNA was extracted following the protocol of FastDNA SPIN Kit. The DNA samples were dissolved with a final dilution in $100-\mu \mathrm{L}$ deionized water and preserved at $-80^{\circ} \mathrm{C}$ until further processing. The DNA concentrations were quantified in duplicate with a Nano-Drop spectrophotometer (Thermo Fisher Scientific Inc., Wilmington, DE, USA). The quantitative PCR primers were Arch_334F (5'ACGGGGCGCAGCAGGCGCGA3 $\left.{ }^{\prime}\right) /$ Arch $_{-}$ 518R (5'ATTACCGCGGCTGCTGG3') for total archaeal 16S gene quantification (Bano et al., 2004), GII-554f (5'GTCGMTTTTATTGGGCCTAA3 $\left.{ }^{\prime}\right)$, and Eury806-r (5'CACAGCGTTTACACCTAG3') for MG-II Euryarchaeota 16S gene quantification (Massana et al., 1997; Teira et al., 2004). The $\mathrm{qPCR}$ analysis was performed at $95^{\circ} \mathrm{C}$ for $30 \mathrm{~s}$ and 40 cycles at $94^{\circ} \mathrm{C}$ for $30 \mathrm{~s}, 55^{\circ} \mathrm{C}$ for total archaea and $53^{\circ} \mathrm{C}$ for MG-II Euryarchaeota for $30 \mathrm{~s}$ and $68^{\circ} \mathrm{C}$ for $1 \mathrm{~min}$. Triplicate measurements were run for each sample and standard.

PCR bands of $16 \mathrm{~S}$ rRNA gene and MG-II gene were amplified from SPM samples in Station M. They were recovered by a Gel Extraction Kit (omega) and sequenced on the 3730sequencing platform. The sequences were annotated as the corresponding target genes, which demonstrated the specificity of the chosen qPCR primers. A dilution series of purified DNA from those positive clones were used as standards. A melting curve analysis was performed to demonstrate that the fluorescent signal obtained in a given reaction was consistent with the expected profile for specific PCR products. The $R^{2}$ values of standard curves were $>0.99$. The efficiency of each qPCR was between 87 and $99 \%$.

\section{Amplicon Sequencing of the Archaeal 16S rRNA Gene}

SPM samples collected in river water, mixing water and seawater were selected to conduct MiSeq pyrosequencing targeting the archaeal 16S rRNA gene. In contrast to the qPCR primers, these primers targeted longer sequences to increase the precision of phylogenetic analysis. The primers were Arch_344F (5'ACGGGGCGCAGCAGGCGCGA3') and Arch_915R (5'GTGCTCCCCCGCCAATTCCT3'; Gantner et al., 2011). The MiSeq sequencing was conducted on the MiSeq platform $(2 \times 250 \mathrm{PE}$, Illumina $)$ at the Shanghai Personalbio Biotechnology (Shanghai, China). Mothur (version 1.29.2; Schloss et al., 2009) was applied to filter the raw pyrosequencing data. The selected sequences were analyzed using the QIIME standard pipeline (Caporaso et al., 2010). Taxonomy was assigned according to the Ribosomal Database Project (RDP) classifier 2.2 (minimum confidence of $80 \%$; Cole et al., 2009). The GenBank accession numbers are PRJNA38421 for those archaeal 16S rRNA genes.

\section{Satellite-Derived Surface Water Temperature (SWT)}

The satellite-derived SWT was determined with a spatial resolution of $4 \mathrm{~km}$ from the NOAA advanced very-highresolution radiometer (AVHRR; version 5.2; http://www.nodc. noaa.gov/SatelliteData/pathfinder4km/). The June mean SWT was obtained from the daily averaged values of 30 days in June 2011 (sampling month). The annual mean SWT and winter mean SWT represented 8-year mean values of annual mean temperature (2004-2011) and monthly mean temperature (December-February), respectively, as the surface sediment (top ca. $10 \mathrm{~cm}$ ) collected in this study might represent a deposition of 6-10 years, based on an estimation from Strong et al. (2012).

\section{RESULTS AND DISCUSSION}

TEX $_{86}$-Derived Temperature and Ring Index The $\mathrm{TEX}_{86}$-derived temperature was calculated based on the calibration of Kim et al. [SST $=68.4 \times \log \left(\mathrm{TEX}_{86}\right)+38.6$; (Kim et al., 2010)]. The CL-TEX ${ }_{86}$ temperatures derived from either the SPM or the surface sediments were close to the satellitebased annual mean SWT in the river water and mixing water, station $\mathrm{R}$ and $\mathrm{M}$, respectively; whereas $\mathrm{CL}-\mathrm{TEX}_{86}$ temperatures for the seawater station $S$ were lower than the winter mean SWT (Figure 2). The correspondence between the CL-TEX 86 temperatures derived from SPM and sediment samples $\left(R^{2}=\right.$ $0.70, P<0.01)$ along the salinity gradient indicated that the TEX $_{86}$ signal in the sediment predominantly reflected archaea from the water column, which is consistent with previous studies 


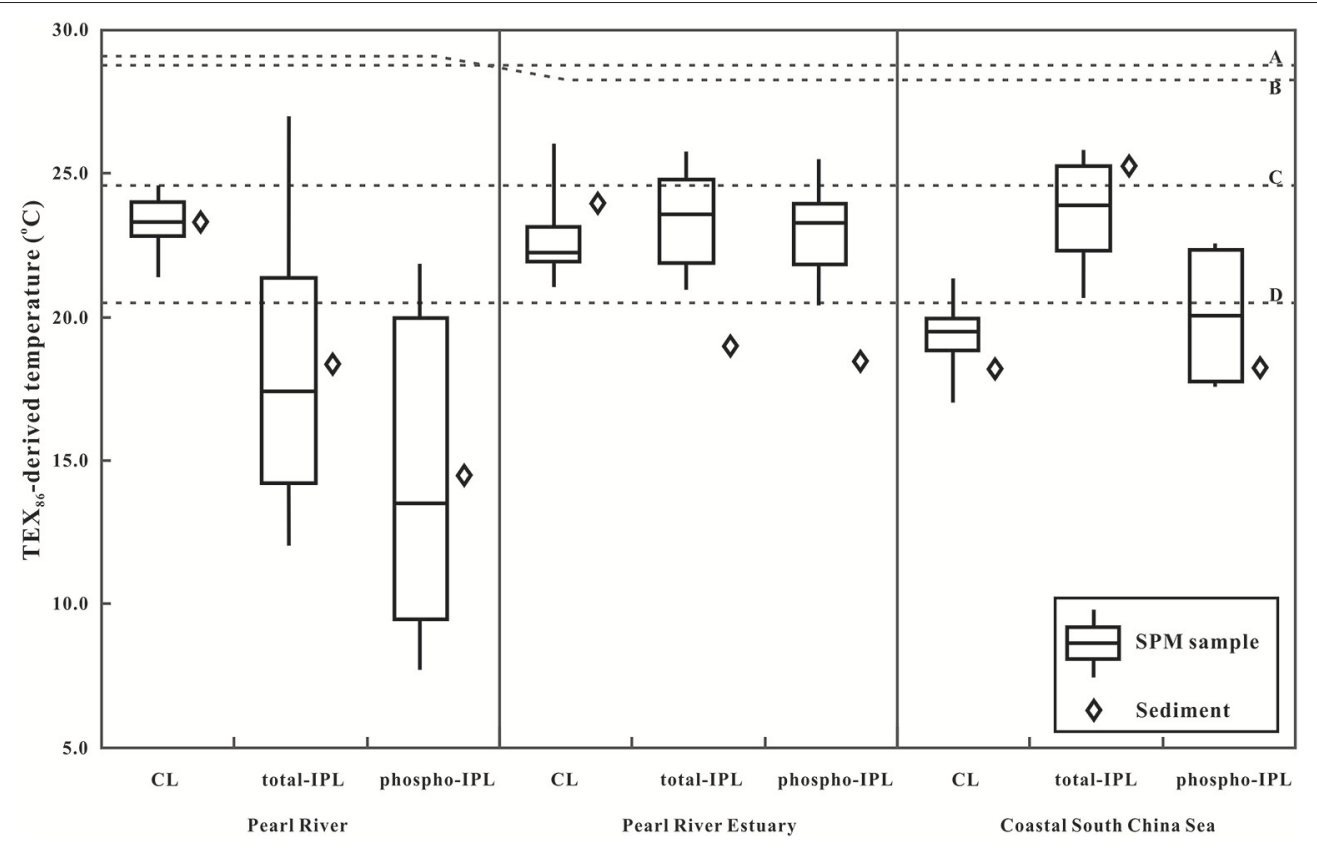

FIGURE 2 | Mean values of TEX 86 -derived temperatures in SPM and surface sediments from the lower Pearl River (R), the PR estuary (M), and coastal SCS (S). CL, core lipids; total-IPL, intact polar lipid based upon acid hydrolysis; phosphor-IPL, intact polar lipid based upon base hydrolysis. Dashed lines A, June mean surface water temperature (SWT; $\left.28.4 \pm 0.07^{\circ} \mathrm{C}\right)$; dashed line $\mathrm{B}$, in situ instrumental temperature $\left(29.1^{\circ} \mathrm{C}\right.$, in the river water; $28.2^{\circ} \mathrm{C}$ in the mixing water and seawater); dashed line C, annual mean SWT $\left(24.71 \pm 0.11^{\circ} \mathrm{C}\right)$; dashed line D, winter SWT $\left(20.54 \pm 0.10^{\circ} \mathrm{C}\right)$.

in the PR estuary (Wang et al., 2015) and other coastal settings (Herfort et al., 2006; Zell et al., 2014).

Total IPL-TEX 86 temperatures in the water column were consistently lower than both the June mean SWT and in situ measurements, although the sampling season was summer (Figure 2). In the mixing water and seawater, the phospho IPLTEX $_{86}$ was lower than the total IPL-TEX 86 whereas it was very close to the CL-TEX 86 (Figure 2; Table 1). Since phosphatidyl head groups can be degraded faster than the glycosidic head groups, the phospho IPL is considered to be a better reflection of the living microorganisms (Harvey et al., 1986; Schouten et al., 2010), which may explain the deviation between these IPL pools. Relatively rapid conversion of phospho IPL to CL may result in more similar ring distributions and thus $\mathrm{TEX}_{86}$ values between phosphor IPL and CL. Furthermore, in the same study area, the variability in $\mathrm{TEX}_{86}$ was suggested to be due to changes in archaeal community composition in the water column, in which the unusually low $\mathrm{TEX}_{86}$-derived temperature in the coastal SCS was speculated to be linked to MG-II Euryarchaeota (Wang et al., 2015).

Since $\mathrm{TEX}_{86}$ can be influenced by factors other than temperature, the ring index was proposed to evaluate the accuracy of $\mathrm{TEX}_{86}$ in marine sediments (Zhang et al., 2016). Here, CL-, phosphor IPL-, and total IPL-TEX 86 values were plotted against $\mathrm{RI}_{1}$ (Equation 2; Figure 3) using data derived from the SPM and surface sediment samples collected during the current and previous studies (Wei et al., 2011; Ge et al., 2013; Zhang et al., 2013; Wang et al., 2015). Most SPM and surface sediment samples from the open South China Sea plotted within the $\mathrm{RI}_{1}-\mathrm{TEX}_{86}$-confined zone $\left[\mathrm{RI}_{1}=3.32 \times\left(\mathrm{TEX}_{86}\right)^{2}-0.77\right.$ $\times \mathrm{TEX}_{86}+1.59, \pm 2 \sigma \sim 0.3$; (Zhang et al., 2016)], whereas the majority of samples from coastal SCS and the PR estuary fell above the calibration zone (Figure 3), exhibiting higher ring index values than those from the open SCS. This implies that the GDGT pool in the water column of the PR estuary and coastal SCS comprised relatively more cyclopentane rings than predicted from the measured SWT. If it is assumed that GDGTs produced only by Thaumarchaeota underpin the relationship between SWT and TEX $_{86}$ (e.g., Schouten et al., 2002), then it follows that either Thaumarchaeota in the PR estuary respond differently to temperature than marine strains, or there is another source of cycloalkyl-containing GDGTs in the estuary.

To further assess the distribution of RI values in the SPM and to explore other contributor(s) to the cyclopentyl GDGT pool in the study area, mean values of CL-, total IPL-, and phospho IPLring index were examined (Figure 4). Note that crenarchaeol, a biomarker for MG-I Thaumarchaeota, was excluded from the ring index calculation $\left(\mathrm{RI}_{2}\right.$, Equation 3$)$ in order to limit its overwhelming influence on the index. The re-defined $\mathrm{RI}_{2}$ equation is more sensitive to the variation of cyclopentanecontaining GDGTs that might be contributed by other archaea. Compared with the river water and seawater, the highest $\mathrm{RI}_{2}$ value for either CL (avg. $0.39 \pm 0.08$ ) or IPL (avg. $0.48 \pm 0.07$ for total IPL; avg. $0.47 \pm 0.10$ for phospho IPL) occurred at station $\mathrm{M}$ in the mixing water (Figure 4; Table 1), suggesting that the PR estuary (station $\mathrm{M}$ ) appeared to be a hot spot of production of GDGTs with cyclopentane moieties. Further confirmation came from the comparison of \%GDGT 1-4 in different water 


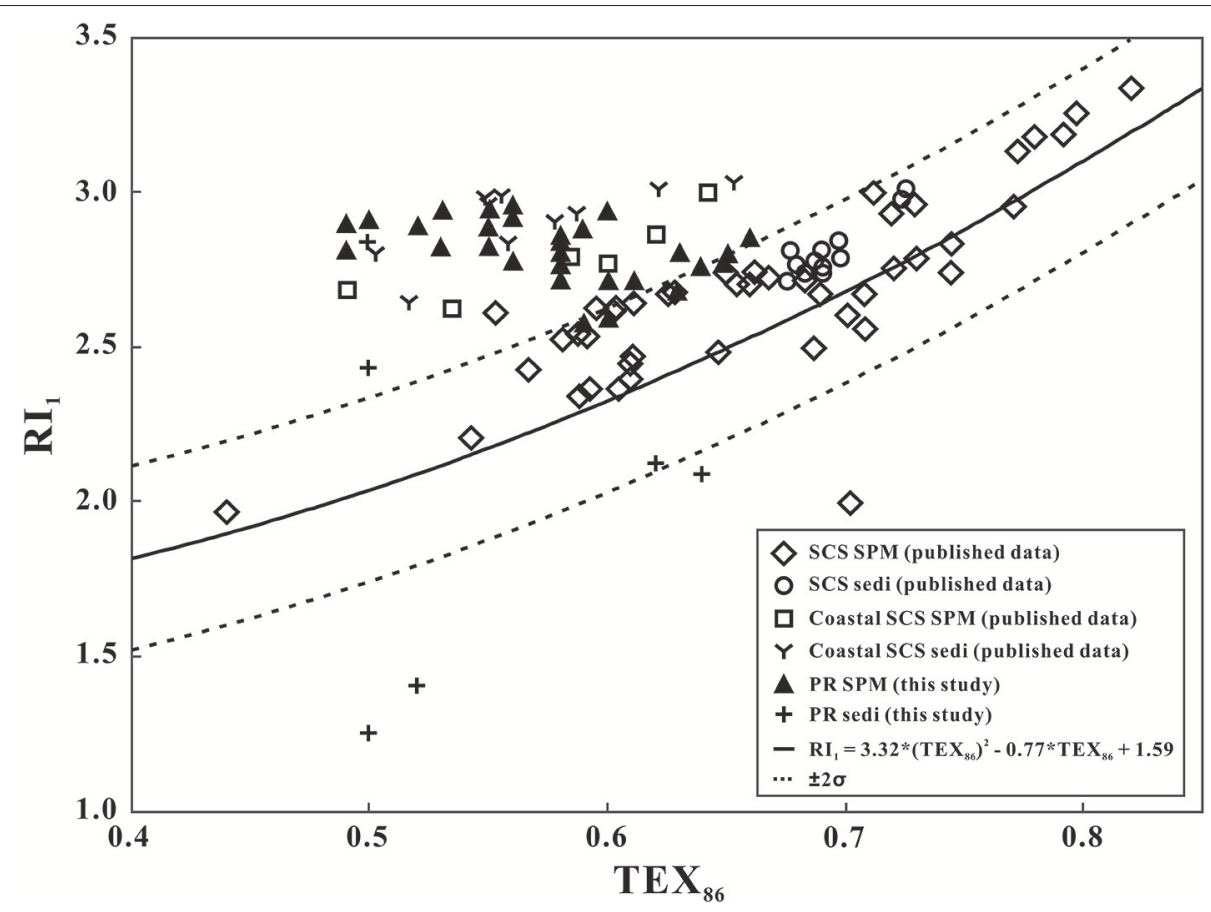

FIGURE 3 | TEX 86 of the PR SPM samples and PR surface sediments plotted against Rl 1 . The solid curve represents the RI-TEX 86 calibration from Zhang et al. (2016). The SCS SPM/sediments and coastal SCS SPM/sediments are from Wei et al. (2011), Ge et al. (2013), Zhang et al. (2013), and Wang et al. (2015).

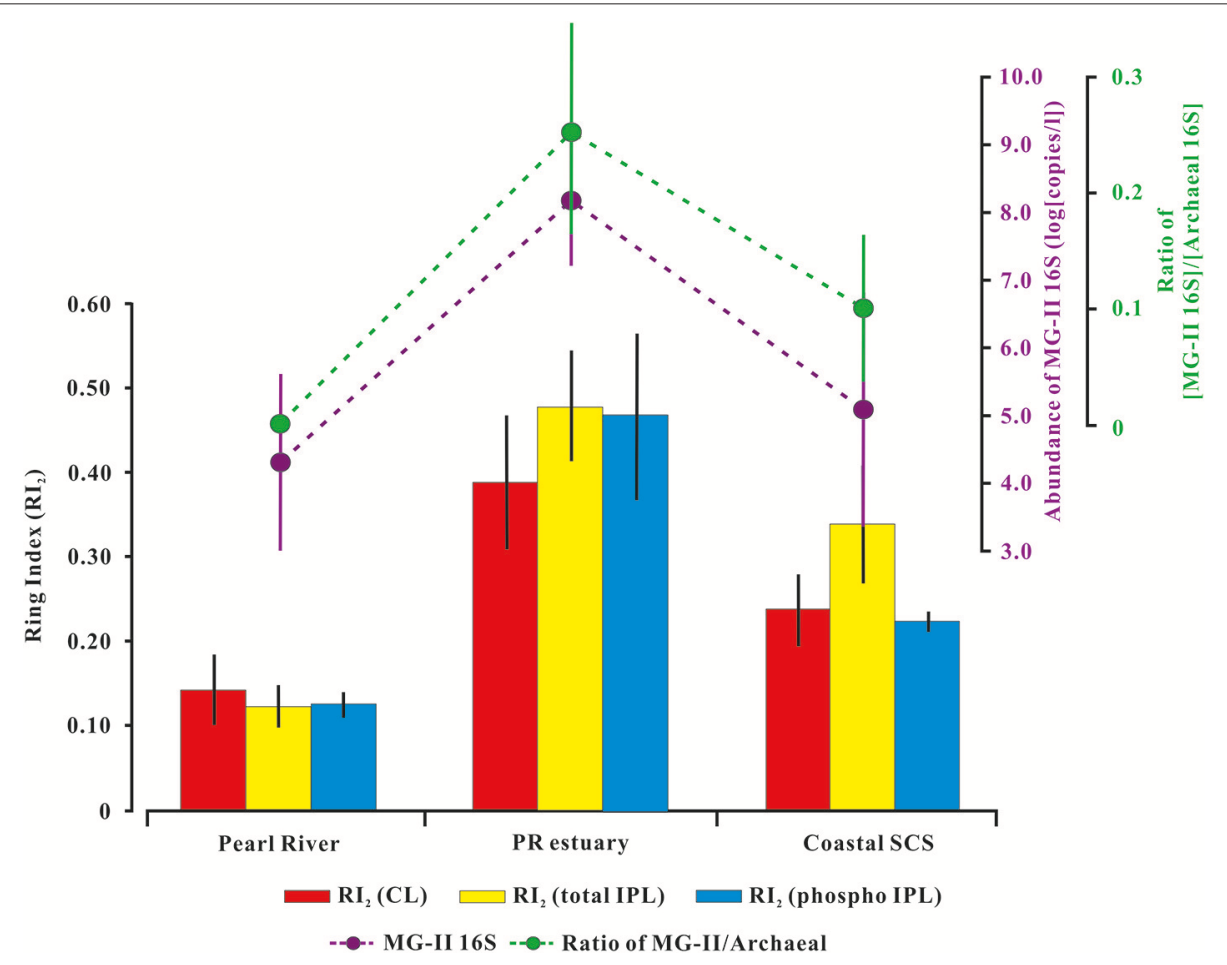

FIGURE 4 | Distribution of the mean values of Ring Index $\left(\mathrm{Rl}_{2}\right)$ compared with the abundance of MG-II Euryarchaeota $16 \mathrm{~S}$ rRNA gene and the gene abundance ratio of MG-II Euryarchaeota to total archaea along the salinity gradient from the river water to seawater. RI (Equation 3) was calculated from CL (red bars), total-IPL (yellow bars), and phosphor-IPL (blue bars). Details are shown in Table 1. 
settings (Table S1), which showed that the sum of the fractional abundances of the GDGTs with 1-4 cyclopentane moieties in the mixing water was significantly higher than that in the seawater or river water. In the mixing water station, the mean values of total IPL-RI and phospho IPL-RI were not significantly different; both were higher than the CL-RI (Figure 4). In the seawater station, however, the total IPL-RI $(0.34 \pm 0.07)$ was more elevated than the phospho IPL-RI $(0.22 \pm 0.01)$ and the CL-RI $(0.24 \pm$ 0.04; Figure 4). This ring index distribution pattern at station $S$ corresponded to the $\mathrm{TEX}_{86}$-temperature distribution in the SPM and sediment samples (Figure 2), suggesting that cyclopentanecontaining GDGTs altered the $\mathrm{TEX}_{86}$ record in the water column, and the vertical transportation of GDGTs from the water column appeared to be a predominant source to the sediment.

\section{Relationship between MG-II Euryarchaeota and Cyclopentane-Containing GDGTs}

Previous studies reported that a significant proportion of MG-II Euryarchaeota was diversely present in the estuarine and coastal regions, including the Pearl River estuary (Liu et al., 2014; Wang et al., 2015), the Yangtze River estuary (Liu M. et al., 2011), and the Jiulong River estuary (Hu et al., 2015). In this study, the MGII Euryarchaeota 16S rRNA gene averaged $5.4 \pm 5.9 \times 10^{8}$ copies $\mathrm{L}^{-1}(n=6)$ at the mixing water station, which was two to three orders of magnitude higher than that in river water station (avg. $1.5 \pm 2.1 \times 10^{5}$ copies $\mathrm{L}^{-1}, n=2$ ) and seawater station (avg. $4.9 \pm 9.4 \times 10^{6}$ copies $\mathrm{L}^{-1}, n=4$; Figure 4). Considering the heterotrophic life style of MG-II, which have been demonstrated by the former genetic analysis (Iverson et al., 2012; Li et al., 2015; Martin-Cuadrado et al., 2015) and cultivation experiment (Orsi et al., 2015, 2016), the high abundances of MG-II in the mixing water station seem to be due to the high phototrophs that enhanced by nutrients input from upper river (Gan et al., 2014).

The ratio of MG-II Euryarchaeota 16S rRNA gene abundance to total archaeal $16 \mathrm{~S}$ rRNA gene abundance ([MG-II $16 \mathrm{~S}] /[$ Archaea 16S]) in mixing water (avg. $0.25 \pm 0.08, n=6$ ) was significantly higher than in the seawater (avg. $0.10 \pm 0.004$, $n=4 ; P<0.01$ ), whereas it was negligible (avg. $<0.0001)$ in the river water (Figure 4). This observation was also supported by pyrosequencing analysis, which exhibited a linear correlation with the qPCR-based ratio of [MG-II]/[Archaea 16S] (Figure S2; Table S2). These results further confirmed that the PR estuary (mixing zone, salinity avg. 16.6) provided a habitat to sustain a natural enrichment of planktonic MG-II Euryarchaeota.

The presence of (more labile) phospho IPL-GDGTs implied in situ production of isoprenoidal GDGTs in the water column along the entire salinity gradient from the Pearl River to coastal SCS. The elevated phospho IPL-RI in the mixing water
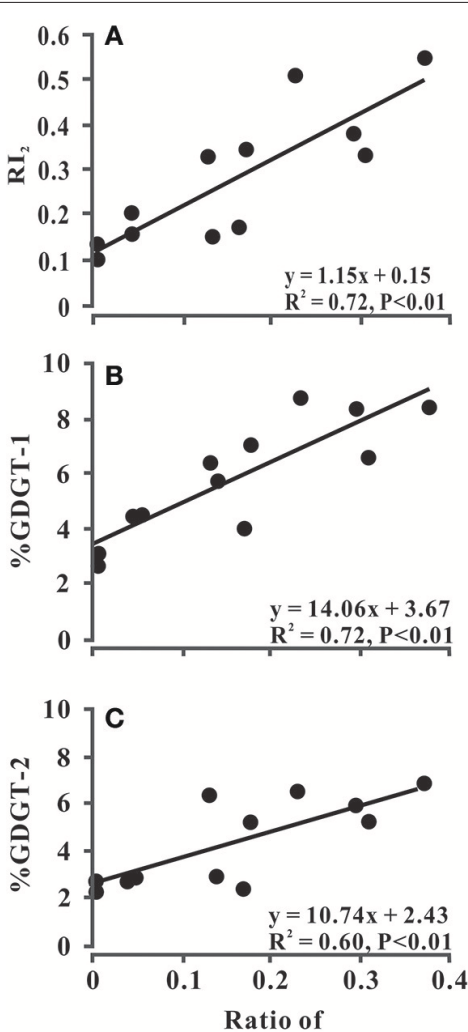

[MG-II 16S]/[Archaeal 16S]
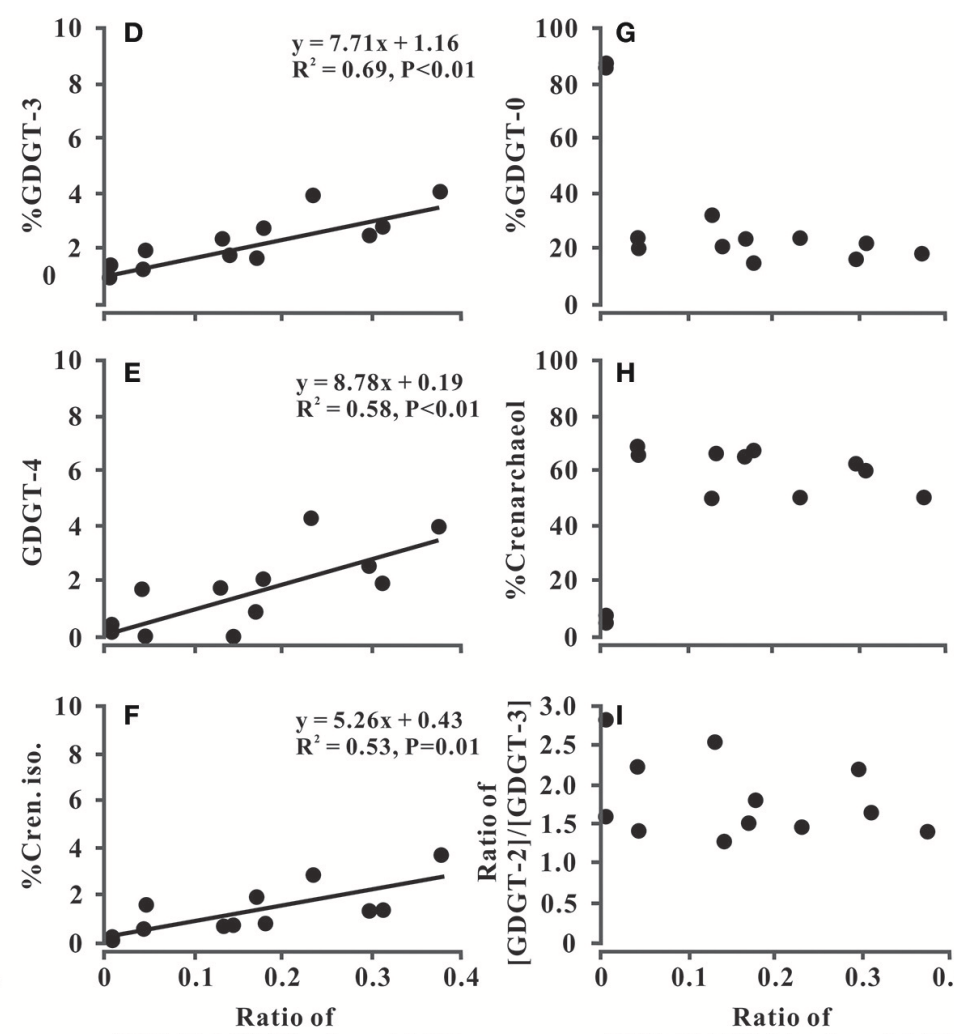

[MG-II 16S]/[Archaeal 16S]

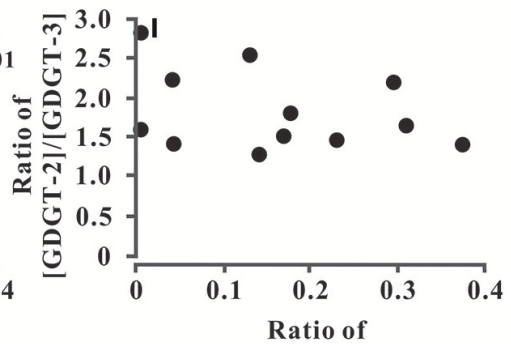

[MG-II 16S]/[Archaeal 16S]

FIGURE 5 | R/ 2 (A), fractional abundance of GDGTs (B-E, G) and Crenarchaeol and isomer (H,F, respectively), and the ratio of GDGT-2 to GDGT-3 (I) vs. the ratio of the MG-II Euryarchaeota 16S rRNA genes to the total archaeal 16S rRNA genes. The black points represent SPM samples collected from the lower Pearl River, the PR estuary, and the coastal SCS. 
additionally suggests that higher relative proportions of GDGTs with 1-4 cyclopentane moieties were produced in the PR estuary. A linear regression analysis confirmed the positive relationship between phospho IPL-derived RI and the [MG-II 16S]/[Archaea $16 \mathrm{~S}]$ ratio in the water column along the salinity gradient $\left(R^{2}\right.$ $=0.72, P<0.01$; Figure 5A). Therefore, it is reasonable to hypothesize that MG-II Euryarchaeota preferentially synthesized GDGTs with 1-4 cyclopentane moieties in this region. Moreover, production of GDGTs-1 to -4 by MG-II Euryarchaeota could represent the missing source needed to explain the elevated value of RI and deviation from the RI-TEX 86 relationship driven by the preservation of Thaumarchaeota GDGTs in global core-top sediments.

To further constrain the relationship between MG-II Euryarchaeota and cyclopentane-containing GDGTs, linear regression analysis was conducted between the fractional abundance of GDGTs and the [MG-II 16S]/[Archaea 16S] ratio in the SPM along the salinity gradient. Results exhibited a significantly positive linear correlation between the [MGII 16S]/[Archaea 16S] ratio and the fractional abundance of phospho IPL-based GDGT with cyclopentane moieties (Figures 5B-F). In contrast, we observed no correlation between the [MG-II 16S]/[Archaea 16S] ratio and the fractional abundances of phospho IPL-based GDGT-0 or crenarchaeol (Figures 5G,H; Table 2). Similar trends of the linear correlations were also observed between the [MG-II 16S]/[Archaea 16S] ratio and the CL- and total IPL-GDGTs with 1-4 cyclopentane moieties, with a less significant correlation between the [MG-II 16S]/[Archaea 16S] ratio and the total IPL-based crenarchaeol regioisomer (Table 2). Although MG-II Euryarchaeota were suggested to be an alternative source of crenarchaeol in the ocean (Lincoln et al., 2014a), our study showed an absence of a significant correlation between the distribution of MGII Euryarchaeota and crenarchaeol (Figure 5H). However, members of MG-II Euryarchaeota living in the North Pacific Subtropical Gyre (i.e., those targeted by Lincoln et al., 2014a) may be different from those living in the coastal zone of the PR estuary. This is consistent with the phylogenetic distribution of MG-II reported by Wang et al. (2015), which showed diverse groups of MG-II living in this region.

By comparison of the $R^{2}$ values and slopes of the regression equations (Figures 5B-F), GDGT-1 exhibited not only the strongest correlation with MG-II Euryarchaeota in the study area, but also largest relative enrichment (i.e., slope of 14.06). If MG-II Euryarchaeota preferentially synthesized GDGT-1, additional contribution of GDGT-1 to the water column of the PR estuary and the coastal SCS would be reflected by an increase in RI values and a substantial decrease in TEX $_{86}$ values. Offsets in $\mathrm{TEX}_{86}$ values have been similarly proposed to result from the decreased ratio of GDGT-2 to GDGT-3 in the surface sediments of this area (Wang et al., 2015), whereas the increased ratio of GDGT-2 over GDGT-3 in the deep-water column seems to be responsible for a warm bias of $\mathrm{TEX}_{86^{-}}$ derived temperature in other marine environments (Taylor et al., 2013; Hernandez-Sanchez et al., 2014). In this study, however, no correlation is exhibited between GDGT-2/3 ratio and [MG-II 16S]/[Archaea 16S] ratio (Figure 5I). A recent study by Kim et al.
TABLE 2 | Regression analysis between the ratio of MG-II 16S rRNA genes to Archaeal 16S rRNA genes vs. the fractional abundance of GDGTs, ring index $\left(\mathrm{Rl}_{2}\right)$, and the ratio of GDGT-2 to GDGT-3.

\begin{tabular}{|c|c|c|c|c|c|c|}
\hline & \multicolumn{2}{|c|}{$\begin{array}{c}\text { [MG-II/Archaea] } \\
\text { vs. } \mathrm{CL}^{\mathrm{a}}\end{array}$} & \multicolumn{2}{|c|}{$\begin{array}{c}\text { [MG-II/Archaea] } \\
\text { vs. total-IPL }\end{array}$} & \multicolumn{2}{|c|}{$\begin{array}{l}\text { [MG-II/Archaea] } \\
\text { vs. phospho-IPL }\end{array}$} \\
\hline & $R^{2}$ & $P$-value & $R^{2}$ & $P$-value & $R^{2}$ & $P$-value \\
\hline \%GDGT-0 & 0.37 & 0.04 & 0.44 & 0.02 & 0.40 & 0.03 \\
\hline \%GDGT-1 & 0.50 & 0.01 & 0.58 & 0.00 & 0.72 & 0.00 \\
\hline \%GDGT-2 & 0.43 & 0.02 & 0.47 & 0.01 & 0.60 & 0.00 \\
\hline \%GDGT-3 & 0.33 & 0.05 & 0.51 & 0.01 & 0.69 & 0.00 \\
\hline \%GDGT-4 & 0.43 & 0.02 & 0.46 & 0.02 & 0.58 & 0.00 \\
\hline \%Cren. & 0.25 & 0.10 & 0.37 & 0.03 & 0.21 & 0.13 \\
\hline \%Cren.iso & 0.56 & 0.01 & 0.11 & 0.80 & 0.53 & 0.01 \\
\hline $\mathrm{Rl}_{2}$ & 0.49 & 0.01 & 0.50 & 0.01 & 0.72 & 0.00 \\
\hline GDGT 2/3 & 0.13 & 0.25 & 0.30 & 0.07 & 0.11 & 0.29 \\
\hline
\end{tabular}

a [MG-II/Archaea], the 16S rRNA gene ratio of MG-II to archaeal. CL, core lipids; total-IPL, intact polar lipids derived upon acid hydrolysis; phospho-IPL, intact polar lipids derived upon base hydrolysis.

(2015) suggested that coincident increases in GDGT-2 and the crenarchaeol regioisomer and decreases in GDGT-1 and GDGT-3 shifted $\mathrm{TEX}_{86}$-derived temperatures toward higher values in the deep-water surface sediments of the Mediterranean Sea. In combination with our data (Figures 4, 5), these observations are consistent with the interpretation that planktonic Euryarchaeota have the potential to bias $\mathrm{TEX}_{86}$ by changing the distribution of TEX $_{86}$-related GDGTs (especially those with 1-3 cyclopentane rings) in different marine environments.

\section{CONCLUSIONS}

This study assessed the relationship between $\mathrm{TEX}_{86}$-related GDGTs and MG-II Euryarchaeota along a salinity gradient from river water to seawater. The fractional abundance of MG-II Euryarchaeota was correlated with \%GDGTs with cyclopentane moieties as well as ring index values, implying that MG-II Euryarchaeota may contribute ringed GDGTs to the total GDGT pool. This source would thus increase the ring index value and potentially bias the $\mathrm{TEX}_{86}$ proxy. However, MG-II Euryarchaeota living in the estuary and coastal region did not seem to be a significant source of crenarchaeol. These and other findings based on environmental distributions provide indirect evidence of the lipid profile of MG-II Euryarchaeota, which cannot be validated until a pure culture is available.

\section{AUTHOR CONTRIBUTIONS}

JW and CZ designed this study. JW extracted and analyzed lipids. WX extracted and analyzed DNA. JW, WX, YZ, TM, and CZ wrote the paper.

\section{ACKNOWLEDGMENTS}

We thank Huangmin Ge, Geng Wu, and Chao Li for helping with the sampling. Songze Chen helped performing the qPCR analysis. We appreciate Dr. Ding He (Zhejiang Uni.) for commenting 
on an earlier version of the manuscript. An early version of this manuscript was discussed online at the Biogeosciences Discussion forum (doi: 10.5194/bgd-12-12455-2015); however, the final paper was declined for publication by Biogeosciences. This research was supported by the National Key Basic Research Program of China grant \#2013CB955703 and 2016YFA0601101 (CZ), and the National Science Foundation of China Grant \# 41530105 and 41673073 (CZ). This study is also a contribution to the international IMBER project. Comments from the two reviewers and the editor significantly improved the quality of the paper and are greatly appreciated.

\section{REFERENCES}

Bano, N., Ruffin, S., Ransom, B., and Hollibaugh, J. T. (2004). Phylogenetic composition of Arctic Ocean archaeal assemblages and comparison with Antarctic assemblages. Appl. Environ. Microbiol. 70, 781-789. doi: 10.1128/AEM.70.2.781-789.2004

Blaga, C. I., Reichart, G. J., Heiri, O., and Sinninghe Damsté, J. S. (2009). Tetraether membrane lipid distributions in lake particulate matter and sediments: a study of 47 European lakes along a North-South transect. J. Paleolimnol. 41, 523-540. doi: 10.1007/s10933-008-9242-2

Bligh, E. G., and Dyer, W. J. (1959). A rapid method of total lipid extraction and purification. Can. J. Biochem. Physiol. 37, 911-917. doi: 10.1139/y59-099

Caporaso, J. G., Kuczynski, J., Stombaugh, J., Bittinger, K., Bushman, F. D., Costello, E. K., et al. (2010). QIIME allows analysis of highthroughput community sequencing data. Nat. Methods 7, 335-336. doi: $10.1038 /$ nmeth.f.303

Cole, J. R., Wang, Q., Cardenas, E., Fish, J., Chai, B., Farris, R. J., et al. (2009). The Ribosomal Database Project: improved alignments and new tools for rDNA analysis. Nucleic Acids Res. 37, D141-D145. doi: 10.1093/nar/gkn879

DeLong, E. F. (1992). Archaea in coastal marine environments. Proc. Natl. Acad. Sci. U.S.A. 89, 5685-5689. doi: 10.1073/pnas.89.12.5685

Galand, P. E., Gutierrez-Provecho, C., Massana, R., Gasol, J., and Casamayor, E. O. (2010). Interannual recurrence of archaeal assemblages in the coastal NW Mediterranean Sea. Limnol. Oceanogr. 55, 2117-2125. doi: 10.4319/lo.2010.55.5.2117

Gan, J., Lu, Z., Cheung, A., Dai, M., Liang, L., Harrison, P. J., et al. (2014). Assessing ecosystem response to phosphorus and nitrogen limitation in the Pearl River plume using the Regional Ocean Modeling System (ROMS). J. Geophys. Res 119, 8858-8877. doi: 10.1002/2014JC009951

Gantner, S., Andersson, A. F., Alonso-Saez, L., and Bertilsson, S. (2011). Novel primers for $16 \mathrm{~S}$ rDNA-based archaeal community analyses in environmental samples. J. Microbiol. Methods 84, 12-18. doi: 10.1016/j.mimet.2010.10.001

Ge, H., Zhang, C. L., Dang, H. Y., Zhu, C., and Jia, G. D. (2013). Distribution of tetraether lipids in surface sediments of the northern South China Sea: implications for $\mathrm{TEX}_{86}$ proxies. Geosci. Front. 4, 223-229. doi: 10.1016/j.gsf.2012.10.002

Harvey, H. R., Fallon, R. D., and Patton, J. S. (1986). The effect of organic matter and oxygen on the degradation of bacterial membrane lipids in marine sediments. Geochim. Cosmochim. Acta 50, 795-804. doi: 10.1016/0016-7037(86)90355-8

Herfort, L., Schouten, S., Boon, J. P., and Sinninghe Damsté, J. S. (2006). Application of the $\mathrm{TEX}_{86}$ temperature proxy in the southern North Sea. Org. Geochem. 37, 1715-1726. doi: 10.1016/j.orggeochem.2006.07.021

Hernandez-Sanchez, M. T., Woodward, E. M. S., Taylor, K. W. R., Henderson, G. M., and Pancost, R. D. (2014). Variations in GDGT distributions through the water column in the South East Atlantic Ocean. Geochim. Cosmochim. Acta 132, 337-348. doi: 10.1016/j.gca.2014.02.009

Hugoni, M., Taib, N., Debroas, D., Domaizon, I., Dufournel, I. J., Bronner, G., et al. (2013). Structure of the rare archaeal biosphere and seasonal dynamics of active ecotypes in surface coastal waters. Proc. Natl. Acad. Sci. U.S.A. 110, 6004-6009. doi: $10.1073 /$ pnas. 1216863110

Hu, A., Hou, L., and Yu, C.-P. (2015). Biogeography of planktonic and benthic archaeal communities in a subtropical eutrophic estuary of China. Microbiol. Ecol. 70, 322-355. doi: 10.1007/s00248-015-0597-4

\section{SUPPLEMENTARY MATERIAL}

The Supplementary Material for this article can be found online at: https://www.frontiersin.org/articles/10.3389/fmicb. 2017.02077/full\#supplementary-material

Figure S1 | Structures of archaeal core GDGTs described in the text.

Figure S2 | Relationship of fractional abundances of MG-I| Euryarchaeota derived from quantitative polymerase chain reaction (qPCR) and pyrosequencing. \% MG-II (qPCR) is calculated based on the ratio of MG-II 16S rRNA gene to Archaea 16S rRNA gene; \% MG-II (sequencing) refers to the fractional abundance of the MG-II OTUs to the total archaeal OTUs.

Huguet, C., Hopmans, E. C., Febo-Ayala, W., Thompson, D. H., Sinninghe Damsté, J. S., and Schouten, S. (2006). An improved method to determine the absolute abundance of glycerol dibiphytanyl glycerol tetraether lipids. Org. Geochem. 37, 1036-1041. doi: 10.1016/j.orggeochem.2006. 05.008

Iverson, V., Morris, R. M., Frazar, C. D., Berthiaume, C. T., Morales, R. L., and Armbrust, E. V. (2012). Untangling genomes from metagenomes: revealing an uncultured class of marine Euryarchaeota. Science 335, 587-590. doi: $10.1126 /$ science. 1212665

Karner, M., DeLong, E. F., and Karl, D. M. (2001). Archaeal dominance in the mesopelagic zone of the Pacific Ocean. Nature 409, 507-510. doi: $10.1038 / 35054051$

Kim, J.-H., Schouten, S., Hopmans, E. C., Donner, B., and Sinninghe Damst,é, J. S. (2008). Global core-top calibration of the TEX $_{86}$ paleothermometer in the ocean. Geochim. Cosmochim. Acta 72, 1154-1173. doi: 10.1016/j.gca.2007.12.010

Kim, J.-H., van der Meer, J., Schouten, S., Helmke, P., Willmott, V., Sangiorgi, F., et al. (2010). New indices and calibrations derived from the distribution of crenarchaeal isoprenoid tetraether lipids: implications for past sea surface temperature reconstructions. Geochim. Cosmochim. Acta 74, 4639-4654. doi: 10.1016/j.gca.2010.05.027

Kim, J. H., Schouten, S., Rodrigo-Gamiz, M., Rampen, S., Marino, G., Huguet, C., et al. (2015). Influence of deep-water derived isoprenoid tetraether lipids on the $\mathrm{TEXH}_{86}$ paleothermometer in the Mediterranean Sea. Geochim. Cosmochim. Acta 150, 125-141. doi: 10.1016/j.gca.2014.11.017

Lee, K. E., Kim, J.-H., Wilke, I., Helmke, P., and Schouten, S. (2008). A study of the alkenone, $\mathrm{TEX}_{86}$, and planktonic foraminifera in the Benguela Upwelling System: Implications for past sea surface temperature estimates. Geochem. Geophys. Geosyst. 9:Q10019. doi: 10.1029/2008GC002056

Li, M., Baker, B. J., Anantharaman, K., Jain, S., Breier, J. A., and Dick, G. J. (2015). Genomic and transcriptomic evidence for scavenging of diverse organic compounds by widespread deep-sea archaea. Nat. Commun. 6:8933. doi: $10.1038 /$ ncomms 9933

Liu, M., Xiao, T., Wu, Y., Zhou, F., and Zhang, W. (2011). Temporal distribution of the archaeal community in the Changjiang Estuary hypoxia area and the adjacent East China Sea as determined by denaturing gradient gel electrophoresis and multivariate analysis. Can. J. Microbiol. 57, 504-513. doi: 10.1139/w11-037

Liu, J., Yu, S., Zhao, M., He, B., and Zhang, X.-H. (2014). Shifts in archaea plankton community structure along ecological gradients of Pearl Estuary. FEMS Microbiol. Ecol. 90, 424-435. doi: 10.1111/1574-6941.12404

Liu, X. L., Lipp, J. S., and Hinrichs, K.-U. (2011). Distribution of intact and core GDGTs in marine sediments. Org. Geochem. 42, 368-375. doi: 10.1016/j.orggeochem.2011.02.003

Lincoln, S. A., Wai, B., Eppley, J. M., Church, M. J., Summons, R. E., and DeLong, E. F. (2014a). Planktonic Euryarchaeota are a significant source of archaeal tetraether lipids in the ocean. Proc. Natl. Acad. Sci. U.S.A. 111, 9858-9863. doi: 10.1073/pnas.1409439111

Lincoln, S. A., Wai, B., Eppley, J. M., Church, M. J., Summons, R. E., and DeLong, E. F. (2014b). Reply to Schouten et al.: marine Group II planktonic Euryarchaeota are significant contributors to tetraether lipids in the ocean. Proc. Natl. Acad. Sci. U.S.A. 111:E4286. doi: 10.1073/pnas.1416736111

Martin-Cuadrado, A.-B., Garcia-Heredia, I., Moltó A. G., López-Úbeda, R., Kimes, N., López-García, P., et al. (2015). A new class of marine Euryarchaeota group 
II from the mediterranean deep chlorophyll maximum. ISME J. 9, 1619-1634. doi: 10.1038/ismej.2014.249

Massana, R., Murray, A. E., Preston, C. M., and DeLong, E. F. (1997). Vertical distribution and phylogenetic characterization of marine planktonic Archaea in the Santa Barbara Channel. Appl. Environ. Microbiol. 63, 50-56.

Orsi, W. D., Smith, J. M., Wilcox, H. M., Swalwell, J. E., Carini, P., Worden, A. Z., et al. (2015). Ecophysiology of uncultivated marine euryarchaea is linked to particulate organic matter. ISME J. 9, 1747-1763. doi: 10.1038/ismej.2014.260

Orsi, W. D., Smith, J. M., Liu, S., Liu, Z., Sakamoto, C. M., Wilken, S., et al. (2016). Diverse, uncultivated bacteria and archaea underlying the cycling of dissolved protein in the ocean. ISME J. 10, 2158-2173. doi: 10.1038/ismej.2016.20

Pitcher, A., Hopmans, E. C., Schouten, S., and Sinninghe Damsté, J. S. (2009). Separation of core and intact polar archaeal tetraether lipids using silica columns: insights into living and fossil biomass contributions. Org. Geochem. 40, 12-19. doi: 10.1016/j.orggeochem.2008.09.008

Pitcher, A., Hopmans, E. C., Mosier, A. C., Francis, C. A., Reese, S. K., Schouten, S., et al. (2011a). Distribution of core and intact polar tetraether lipids in enrichment cultures of Thaumarchaeota from marine sediments. Appl. Environ. Microbiol. 77, 3468-3477.

Pitcher, A., Villanueva, L., Hopmans, E. C., Schouten, S., Reichart, G. J., and Sinninghe Damsté, J. S. (2011b). Niche segregation of ammonia-oxidizing archaea and anammox bacteria in the Arabian Sea oxygen minimum zone. ISME J. 5, 1896-1904. doi: 10.1038/ismej.2011.60

Schloss, P. D., Westcott, S. L., Ryabin, T., Hall, J. R., Hartmann, M., Hollister, E. B., et al. (2009). Introducing mothur: opensource, platformindependent, community-supported software for describing and comparing microbial communities. Appl. Environ. Microbiol. 75, 7537-7541. doi: 10.1128/AEM.01541-09

Schouten, S., Hopmans, E. C., Schefuß, E., and Sinninghe Damsté, J. S. (2002). Distributional variations in marine crenarchaeotal membrane lipids: a new tool for reconstructing ancient sea water temperatures? Earth Planet. Sci. Lett. 204, 265-274. doi: 10.1016/S0012-821X(02)00979-2

Schouten, S., Huguet, C., Hopmans, E. C., and Sinninghe Damsté, J. S. (2007). Improved analytical methodology of the $\mathrm{TEX}_{86}$ paleothermometry by high performance liquid chromatography/atmospheric pressure chemical ionization-mass spectrometry. Anal. Chem. 79, 2940-2944. doi: $10.1021 / \mathrm{ac} 062339 \mathrm{v}$

Schouten, S., Hopmans, E. C., Baas, M., Boumann, H., Standfest, S., Könneke, M., et al. (2008). Intact membrane lipids of "Candidatus Nitrosopumilus maritimus", a cultivated representative of the cosmopolitan mesophilic Group I Crenarchaeota. Appl. Environ. Microbiol. 74, 2433-2440. doi: 10.1128/AEM.01709-07

Schouten, S., Middelburg, J. J., Hopmans, E. C., and Sinninghe Damsté, J. S. (2010). Fossilization and degradation of intact polar lipids in deep subsurface sediments: a theoretical approach. Geochim. Cosmochim. Acta 74, 3806-3814. doi: 10.1016/j.gca.2010.03.029

Schouten, S., Hopmans, E. C., and Sinninghe Damsté, J. S. (2013). The organic geochemistry of glycerol dialkyl glycerol tetraether lipids: a review. Org. Geochem. 54, 19-61. doi: 10.1016/j.orggeochem.2012.09.006

Schouten, S., Villanueva, L., Hopmans, E. C., van der Meer, M. T. J., and Sinninghe Damsté, J. S. (2014). Are Marine Group II Euryarchaeota significant contributors to tetraether lipids in the ocean? Proc. Natl. Acad. Sci. U.S.A. 111:E4285. doi: 10.1073/pnas.1416176111

Sinninghe Damsté, J. S., Hopmans, E. C., Schouten, S., van Duin, A. C. T., and Geenevasen, J. A. J. (2002). Crenarchaeol: the characteristic core glycerol dibiphytanyl glycerol tetraether membrane lipid of cosmopolitan pelagic crenarchaeota. J. Lipid Res. 43, 1641-1651. doi: 10.1194/jlr.M200148JLR200

Sinninghe Damsté, J. S., Ossebaar, J., Schouten, S., and Verschuren, D. (2012). Distribution of tetraether lipids in the 25-kyr sedimentary record of Lake Challa: extracting reliable $\mathrm{TEX}_{86}$ and MBT/CBT palaeotemperatures from an equatorial African lake. Quat. Sci. Rev. 50, 43-54. doi: 10.1016/j.quascirev.2012.07.001

Strong, D. J., Flecker, R., Valdes, P. J., Wilkinson, I. P., Rees, J. G., Zong, Y. Q., et al. (2012). Organic matter distribution in the modern sediments of the Pearl River Estuary. Org. Geochem. 49, 68-82. doi: 10.1016/j.orggeochem.2012.04.011

Taylor, K. W. R., Huber, M., Hollis, C. J., Hernandez-Sanchez, M. T., and Pancost, R. D. (2013). Reevaluating modern and palaeogene GDGT distributions: impalications for SST reconstructions. Global Planet. Change 108, 158-174. doi: 10.1016/j.gloplacha.2013.06.011

Teira, E., Reinthaler, T., Pernthaler, A., Pernthaler, J., and Herndl, G. J. (2004). Combining catalyzed reporter deposition-fluorescence in situ hybridization and microautoradiography to detect substrate utilization by Bacteria and Archaea in the deep ocean. Appl. Environ. Microbiol. 70, 4411-4414. doi: 10.1128/AEM.70.7.4411-4414.2004

Turich, C., Freeman, K. H., Bruns, M. A., Conte, M., Jones, A. D., and Wakeham, S. G. (2007). Lipids of marine Archaea: patterns and provenance in the water-column and sediments. Geochim. Cosmochim. Acta 71, 3272-3291. doi: 10.1016/j.gca.2007.04.013

Wang, J.-X., Wei, Y., Wang, P., Hong, Y., and Zhang, C. L. (2015). Unusually low $\mathrm{TEX}_{86}$ values in the transitional zone between Pearl River estuary and coastal South China Sea: impact of changing archaeal community composition. Chem. Geol. 402, 18-29. doi: 10.1016/j.chemgeo.2015.03.002

Wei, Y., Wang, J. X., Liu, J., Dong, L., Li, L., Wang, H., et al. (2011). Spatial variations in Archaeal lipids of surface water and core-top sediments in the South China Sea: implications for paleoclimate studies. Appl. Environ. Microbiol. 77, 7479-7489. doi: 10.1128/AEM.00580-11

Weijers, J. W. H., Schouten, S., Spaargaren, O. C., and Sinninghe Damst,é, J. S. (2006). Occurrence and distribution of tetraether membrane in soils: implications for the use of the BIT index and the TEX $\mathrm{X}_{86}$ SST proxy. Org. Geochem. 37, 1680-1693. doi: 10.1016/j.orggeochem.2006.07.018

Weijers, J. W. H., Lima, K. H. L., Aquilina, A., Sinninghe Damsté, J. S., and Pancost, R. D. (2011a). Biogeochemical controls on glycerol dialkyl glycerol tetraether lipid distributions in sediments characterized by diffusive methane flux. Geochem. Geophys. Geosyst. 12:10. doi: 10.1029/2011GC003724

Weijers, J. W. H., Bernhardt, B., Peterse, F., Werne, J. P., Dungait, J. A. J., Schouten, S., et al. (2011b). Absence of seasonal patterns in MBT-CBT indices in mid-latitude soils. Geochim. Cosmochim. Acta 75, 3179-3190. doi: 10.1016/j.gca.2011.03.015

Zell, C., Kim, J.-H., Hollander, D., Lorenzoni, L., Baker, P., Silva, C. G., et al. (2014). Sources and distributions of branched and isoprenoid tetraether lipids on the Amazon shelf and fan: Implications for the use of GDGTbased proxies in marine sediments. Geochim. Cosmochim. Acta 139, 293-312. doi: 10.1016/j.gca.2014.04.038

Zhang, C. L., Wang, J.-X., Wei, Y., Zhu, C., Huang, L., and Dong, H. (2012). Production of branched tetraether lipids in the lower Pearl River and estuary: effects of extraction methods and impact on bGDGTs proxies. Front. Terr. Microbiol. 2:274. doi: 10.3389/fmicb.2011.00274

Zhang, J., Bai, Y., Xu, S., Lei, F., and Jia, G. (2013). Alkenone and tetraether lipids reflect different seasonal seawater temperatures in the coastal northern South China Sea. Org. Geochem. 58, 115-120. doi: 10.1016/j.orggeochem.2013.02.012

Zhang, Y. G., Zhang, C. L., Liu, X. L., Li, L., Hinrichs, K.-U., and Noakes, J. E. (2011). Methane Index: a tetraether archaeal lipid biomarker indicator for detecting the instability of marine gas hydrates. Earth Planet. Sci. Lett. 307, 525-534. doi: 10.1016/j.epsl.2011.05.031

Zhang, Y. G., Pagani, M., and Wang, Z. (2016). Ring Index: a new strategy to evaluate the integrity of $\mathrm{TEX}_{86}$ paleothermometry. Paleoceanography 31, 220-232. doi: 10.1002/2015PA002848

Zhu, C., Weijers, J. W. H., Wagner, T., Pan, J. M., Chen, J. F., and Pancost, R. D. (2011). Sources and distributions of tetraether lipids in surface sediments across a large riverdominated continental margin. Org. Geochem. 42, 376-386. doi: 10.1016/j.orggeochem.2011.02.002

Conflict of Interest Statement: The authors declare that the research was conducted in the absence of any commercial or financial relationships that could be construed as a potential conflict of interest.

The reviewer FS declared a shared affiliation, with no collaboration, with several of the authors to the handling Editor.

Copyright $\odot 2017$ Wang, Xie, Zhang, Meador and Zhang. This is an open-access article distributed under the terms of the Creative Commons Attribution License (CC $B Y)$. The use, distribution or reproduction in other forums is permitted, provided the original author(s) or licensor are credited and that the original publication in this journal is cited, in accordance with accepted academic practice. No use, distribution or reproduction is permitted which does not comply with these terms. 